\title{
THE RELEVANCE OF THE PROBLEM OF TRAINING LEGAL INTERPRETERS AND TRANSLATORS
}

\author{
Irina Meshkova ${ }^{1}$, Olga Sheremetieva ${ }^{2}$ \\ ${ }^{1}$ Assoc Prof., PhD RUDN University, RUSSIA, meshiran1@gmail.com \\ ${ }^{2}$ Senior Lecturer RUDN University, RUSSIA, oasher@mail.ru
}

\begin{abstract}
During the past years, there has been a significant growth in international contacts, professional, economic and cultural ties. New information technologies have influenced all spheres of social and professional life. Nevertheless, despite the abundance of various electronic translation resources (automated translation platforms), the need for professional translators/interpreters is not decreasing, but rather increasing.

That is why one of the goals facing foreign language teachers working in non-linguistic faculties is to train high-level special translators/interpreters, including lawyers-translators/interpreters. The main goal of the formation of modern specialists is to master professional qualities, united by the concept of professional competence.

In the learning process, teachers solve the problems of preparing students for real communication, understood as a communicative act between representatives of different cultures. The formation of professional skills of future specialists in the field of legal translation, which includes the acquisition of linguistic, social, cultural, psychological and other skills, is one of the activities of the Department of Foreign Languages of the Law Institute of the RUDN University.

It should be noted that legal translation is one of the most difficult types of translation, the defining characteristic of which is not only a good knowledge of languages, which prevents misunderstanding of texts, but also a deep knowledge of legal terminology, various legal systems of many countries of the world. At the initial stage of training, lexical and grammatical skills and skills of a general foreign language are formed. Subsequent stages of training involve careful work on mastering professional terminology, syntactic and stylistic features of both a foreign and native language.
\end{abstract}

Keywords: learning process, non-linguistic faculties, professional translators/interpreters, professional skills, action-oriented approach, authentic material

\section{INTRODUCTION}

The studied foreign language is realized in two aspects, as a language of general use and as a language of specialty, in our case, le français juridique. Translation/interpreting is understood as a type of speech activity aimed at transmitting a message, and as a process of transmitting a message (Miniar-Beloruchev, 1996). Each type of test has its own special vocabulary, its own terminology when it comes to special texts. The text as a subject of research is considered not only as the main unit of communication, but also as a unit of linguistic and translation research. Any speech activity is impossible without a text, understood not only as a product of speech, but also as a subject of research. The text of any genre from a short note to a multi-page report is the subject of translation and research (Seleskovitch, Lederer, 1984).

Translation activity is a complex process of linguistic and mental activity, taking into account linguistic and extralinguistic factors. Translation is a process of communication that unites the sender, the recipient of the text and the translator/interpreter as an intermediary between them, uniting different languages and cultures 
(Gémar, 2011). Working with legal texts has its own characteristics, with texts of this genre it is necessary to work differently than with literary and journalistic ones. The legal text should be considered from the point of view of legal knowledge and the corresponding linguistic expression. There is a relationship between legal norms and their language expression. Consequently, the question arises of the selection of the appropriate text didactic material.

\section{LITERATURE REVUE AND METHODOLOGIE}

Translation is also considered as an important component of not only interlanguage, but also intercultural communication, and a translator who speaks two languages must know the characteristics of different cultures (Garbovsky, 2007). Specialists understand well what knowledge and skills they should acquire when studying a foreign language; they have formed a certain scientific picture of the world. In most cases, legal language and translation are taught by language teachers who are not legal professionals, but who have an idea of the main components of the law of a particular country. It can be assumed that teaching the translation of texts belonging to different legal systems is based on legal linguistics, the rules and principles of language teaching, taking into account special knowledge.

Legal translation has its own special characteristics. One of the main types of legal texts is law as a product of culture, and it hasits own unique character in each society (Gémar, 2011). Each specialization has its own lexical component, a feature of the legal language is a special system of means of expression. The law is closely related to the language, depends on it, which is especially evident when translating laws from one language into another, providing for the consideration of traditions and the legal system. We can say that language and culture are two of the most important elements defining the very essence of legal translation. (Bocquet, 2008). For the formation of translation competence, various texts are selected that meet such requirements as relevance to a certain genre, relevance of the topic and having characteristic translation difficulties that students learn to identify in texts of different genres, for example, socio-political, legal, etc.

Before the teacher of the language of the specialty there are questions for what purpose, on what material to teach students. Students should be divided according to the level of language proficiency and specialty. It is unlikely that in their first year of law school, students are proficient in all the basic concepts of jurisprudence. To form a picture of the world, lawyers-translators analyze various legal texts (doctrines, resolutions, court decisions), study both general and special vocabulary, consider examples of written and oral discourse, sources of law, articles of court journalists, etc. Translation of scientific, regulatory, administrative and legal texts require compliance with strict rules in accordance with the prevailing picture of the world (Cornu, 2005).

The cultural and stylistic component is extremely important, since translation is viewed as an interaction between language and culture. In addition to the linguistic component, linguistic and cultural specifics should be taken into account (Delisle, 1999). The creation of a full-fledged translation of a text depends on the translator's understanding and mastery of the ethnic and cultural particularities, the ability to convey the text in such a way that it is understandable to carriers of a different culture and helps to overcome cultural barriers. From this point of view, culture is understood as a kind of cognitive mechanism for the accumulation, processing and transmission of cultural values and meanings developed in a particular society (Garbovsky, 2007). Understanding texts related to another culture requires a translator to have certain knowledge and skills. To correctly translate the realities of another culture, background knowledge is required, (présupposition) You can define the translation process as the creation of a linguocultural version based on the source text. The linguocultural aspect is always present in a high-quality translation, since its absence can lead to distortion of information. It includes culturally significant traditions (norms, customs), structural and semantic units of the language, the use of phraseological units and features of the construction of phrases. Cultural features can be conveyed using lexical transformations, at the level of words and phrases (tracing, generalization, replacing the realities of the source language with the realities of the target language, with the help of lexical and grammatical transformations, descriptive translation, compensation, and in some cases, compiling a commentary on the text. In is worth to remember that the key element of interaction between people and the object of translation is the meaning, not only the words (Seleskovitch, Lederer, 1984).

The main purpose of translation is to create communication. The text should be a link between the author of the text and the reader. As for legal translation, it is known that even in ancient times, the features of constructing accusatory and acquittal speeches were distinguished. When teaching legal language and translation, teachers should develop a system of exercises for students so that they can learn to master legal discourse, correctly draw up legal statements, court decisions, annotations in a foreign language, comment on decisions, draw up regulations, cases of legal practice. In order to develop professional skills and abilities of a lawyer-translator, students learn to compose reports on the subject of the studied branch of law, starting 
with finding a problem, establishing links between parts of a text, learning a language in connection with a specific topic, principles of language, linguistic and legal techniques. In order to correctly build a program for teaching a special language and legal translation, one can talk about such a discipline as legal linguistics (Cornu, 2005).

In our time of rapid development of information technology, changes are taking place in all areas of professional activity. While there are various programs for teaching a common language, they are often absent or are paid for teaching translation. There is a problem of systematization of knowledge and skills to improve the qualifications of specialist translators. The purpose of a specialist's training is to form professional translation competence, understood as a set of skills and abilities that allow solving professional problems.

The method of teaching translation is different from teaching a common language, because the goals are different (Civera García, 2012). You must be able to use language as a translation tool. The special text is considered not only as the basic unit of communication, but also as the basic unit of linguistic and translation research. The main goal is to convey the main content of the text of one language by means of another, translating not words, but the meaning. When teaching, for example, written translation, students learn to perform the actual translation of the text, adaptation of the text, abstract translation, resume, while it is necessary to be able to perform various translation transformations, analyze the available translations of parallel texts. Exercises for the development and consolidation of the relevant skills and abilities of translation have been developed and included in the teaching aids for translation from French, prepared by the teachers of the Department of Foreign Languages of the Law Institute of the RUDN University.

As a source of textual material for the training of lawyers-translators, we recommend materials from the websites of the newspapers Figaro, Le Monde, using a computer in the classroom to create conditions as close as possible to real situations (simulation - case study). It is advisable to use Internet technologies when working with parallel texts, i.e. source texts and its published, official translation. So, for example, when working with students studying international law, it is possible to use the official websites of the UN, the $\mathrm{EU}$, the Russian Foreign Ministry, which publish official messages and their official translations. A feature of this type of text is the use of a large number of clichés, and therefore students should learn frequently repeated clichés in order to further use them when translating texts of a certain type, for example, international topic. Comparison of audio and video materials in different languages, pre-translation analysis of the text, analyses of available translations are necessary to consolidate the acquired knowledge and skills. After comparing the available official translations, students can submit their own translation. As a rule, informational texts are small in content, they use well-established lexical, grammatical, stylistic structures, phraseological expressions, accepted forms of politeness.

The experience of the authors of the article shows that after a comparative analysis and mastering of the basic structures, it is possible to use these texts in the classroom for special translation into 2-3 semesters. In most cases, the language of law begins to be studied in the 3rd year (5th semester), when students know the basics of the legal system of their country and the country of the studied language. The teacher is faced with the task of adding the missing knowledge not only in terms of language, but also in the cultural aspect, i.e. a certain synthesis of language and law arises. Special attention should be paid to the study of special vocabulary, abbreviations typical for the selected type of text with the obligatory involvement of background knowledge. Students should be able to compile a glossary based on the keywords of the texts in Russian and French. To consolidate special vocabulary, students in the classroom can read aloud to colleagues in turn prepared thematic texts for interpretation. It can be recommended to perform a reverse translation, when first students translate from a foreign language into their native language, and then the resulting translation back into a foreign one. Thus, the key vocabulary and text structures of the selected topic are repeated several times on different materials. In the last 7-8 semesters, students are offered for translation complex and voluminous texts for special translation, essays, critical articles, translation of interviews, journalistic and scientific texts proper, in which emotionally colored vocabulary on a specific topic can be used. In such complex texts, one should be able to translate play on words, allusions, quotes from the classics, proverbs and sayings, Latinisms, etc. In any case, when starting to translate a text of a certain genre, one should start with a pre-translation analysis of the text, including not only linguistic stylistic, but also cultural analysis.

Students-law translators must know the general vocabulary of the studied language, legal terminology, international vocabulary, borrowings from Latin, legal phraseology, know and be able to correctly translate the grammatical and stylistic features of the legal language both native and foreign. When teaching, special attention should be paid to false friends of the translator, (i.e. words that have different meanings in the 
native language and the target foreign language). An example of such words in a pair of Russian and French can be: parquet - prosecutor's office (not only parquet floor), accompagnement - accompaniment (not only musical accompaniment), accord - agreement, contract, consent (not only chord), faculté - ability; property, opportunity, right, power, authority, goods, cargo (not only in educational establishment faculty or department), pénal - criminal (not a pencil box - plumier).

When teaching legal French legal terminology, it should be borne in mind that legal systems are different, therefore, special attention should be paid to this in order to avoid mistakes in translation. Legal terminology is associated with the country's legal culture, linguistic, cultural and legal traditions (Cornu, 2020). Being an integral part of the language, legal terminology provides the exchange of special information, summarizes the results of professional activities. When teaching legal translation from French, it must be borne in mind that French law is based on Roman law, therefore French legal terminology contains a significant number of Latinisms (fructus, factum notarium, ad hoc, de lege lata, jus tertii, veto). A characteristic feature of French legal terminology is the presence of international legal terms (ratification, verdict, procédure, rapport, doctrine).

Legal texts related to the scientific and business style of speech have the goal of objectively and impartially disclosing the main content (Soignet, 2003). Among the different types of tests of the legal style, a statute, order, order, agreement, instruction, statement, complaint, resolution, etc. are distinguished. Such texts provide business communication and have certain stylistic and expressive features, i.e. they should elicit an appropriate response from the recipient.

\section{EXPERIENCE AND RESULTS}

In recent years, there have been great changes in teaching not only the common language, but also translation. Distance learning and hybrid learning, combining both types of learning, have been added to traditional classroom teaching with a teacher, which has a great advantage, since the use of Internet resources allows students to communicate more during the learning process. Distance learning involves a special teaching methodology. This was especially evident in 2020 during the pandemic, when universities switched to distance learning, which is characterized by the absence of the personal, direct presence of a teacher, communication is possible only on the Internet, using various platforms, for example, Zoom, Microsoft Teams, etc. If we compare traditional education with personal presence and learning using Internet technologies, then we can talk about the diachrony and synchrony of educational processes.

The spread of the Internet and multimedia technologies have led to the use of various methods of communication in teaching and the creation of new methods. When teaching translation from French, the teacher is faced with the task of arousing interest in the French-speaking world, in French society in particular. An important place in oral and written translation is given to materials from bilingual or multilingual sites. To the proposed video materials, teachers develop a system of exercises aimed at understanding the text, speaking, discussing the text and topics in general, compiling a written summary of the audio text, and selecting materials that correspond to the group level. Thus, online materials help to select the most topical material, to work out 4 basic language competencies, adding to them an additional one - translation competence. The use of the communicative-activity method in teaching language and translation, the modernization of teaching involves the use of modern technologies focused on new forms of education, providing for greater independence and activity of students.

Our experience shows that within the framework of this method, it is promising to use, for example, the form of videoconferences, when students communicate with each other, and the role of a mediator can be played by both a teacher and one of the students. For example, during the period of distance learning during the Covid 19 Pandemic, 3-year lawyers-translators finished studying the peculiarities of translating the text of the Statut of the UN Court, learned the key vocabulary, and considered the basic grammatical and stylistic structures. They then wrote a script for the press conference, including key questions related to the topic studied. One of the students was the mediator. Thus, the form of videoconference helped to conduct the final lesson not in the traditional form of a survey by the teacher of students, but made it possible for everyone to participate in the preparation and conduct of the final lesson, making it interesting and interactive for students. The discussion turned out to be very lively, the students demonstrated not only excellent command of the French language and translation skills, but also knowledge of the legal discipline. This was an example of an interdisciplinary approach in teaching a foreign language of a specialty and special translation. In this situation, we can talk about two-way translation, when one student asks a question in a foreign language, the second answers, and the third translates the question and answer.

The teacher's role was to guide the online learning process, to select resources to help solve emerging 
problems. Our research has shown that the use of additional Internet resources contributes to the improvement of students' knowledge and skills. This applies to grammar tests, phonetic exercises (be sure to record yourself for listening), vocabulary exercises with keys to test knowledge. Repeated listening and viewing of materials helps to consolidate the skills of oral speech. The interactive nature of the distance learning method makes it possible for the students to "be present" in the missed class and to do the exercises that the group performed in the class.

\section{CONCLUSION}

The training program proposed by the authors is based on the principles of an interactive, communicative, action-oriented approach, and the system of exercises and various tasks includes exercises aimed at modeling situations that maximally reproduce the professional real context. The proposed teaching methodology provides for a gradual increase in the volume and a stage by stage increase in the complexity of the proposed authentic material (paper texts, audio and video texts, various materials of web pages). Thus, there is a systematic development of all 4 basic competencies, the ability to analyze a variety of special legal information, including that obtained from professional Internet sources, is formed.

The result of the application of such a training system for professional (special) translation is the active participation of students in international legal conferences, round tables held both in the traditional format (with the presence) and in the online format (spring-autumn 2020). Using the knowledge gained, young specialists can further professionally conduct their professional activities in the field of legal translation.

\section{ACKNOWLEDGEMENT}

This paper has been supported by the RUDN University Strategic Academic Leadership Program.

\section{REFERENCE LIST}

Bocquet, C. (2008). La traduction juridique. Fondement et méthode, Paris, DeBoeck-Duculot.

Civera García, P. (2012). Apprendre le français... pour traduire des textes de spécialité. Domaines administratif, économique et juridique. Madrid, Castellón, Edelsa, UJI.

Cornu, G. (2005). Linguistique juridique. Paris, Montchrestien, coll. "Domat. Droit privé", 3e edition.

Cornu, G. (2020). Vocabulaire juridique. Dictionnaires Quadrige, PUF.

Delisle, J. (1999). La terminologie de la traduction, Ottawa, Presses de l'Université d'Ottawa.

Garbovsky, N.K. (2007). Theory of Translation: Proc. 2nd ed. Moscow: Publ. Mosk. Univ. Press.

Gémar, J.-C. (2011). Traduire le droit. Lettre, esprit et équivalence. In : Marie Cornu et Michel Moreau, dir. Traduction du droit et droit de la traduction. Paris : Dalloz.

Miniar-Beloruchev, R.K. (1996). Theory and methods of translation. Moscow.

Seleskovitch, D. et Lederer, M. (1984). Interpréter pour traduire. Paris, Didier Érudition.

Soignet, M. (2003). Le français juridique. Paris, Hachette-FLE. 